\title{
Lifestyle changes and its effect towards the evolution of human dentition
}

\author{
Arofi Kurniawan ${ }^{1 *}\left(\mathbb{D}\right.$, Shafa Marwa Moza ${ }^{2}$, Nathania Nuraini ${ }^{2}$, Mayang Aziza Hanif ${ }^{2}$, Dhea Arum Sekar ${ }^{2}$ and \\ Patricia Talitha ${ }^{2}$
}

\begin{abstract}
Background: The dentition of modern humans has evolved from their hominid ancestors to their current form. Factors regarding the changes of lifestyle such as dietary habits and usage of tools have affected the evolution of human dentition. This article aimed to discuss the effect of dietary changes on the evolution of human teeth. An online literature search in the PubMed database was conducted according to the inclusion criteria of this study.

Main body: The culture transition from a hunter-gatherer society to agriculture is followed by dietary changes, which result in a decrease of tooth wear due to more refined food sources in agricultural intensification. By analyzing the microwear pattern such as shear, striation, and pattern of the buccal teeth, the dietary hypothesis based on the occlusal tooth microwear analysis could be examined.

Conclusion: The dietary hypothesis based on the occlusal tooth microwear study could be tested by analyzing the microwear pattern (shear, striation, pattern) of the buccal teeth. Posterior teeth are more closely related to diet, while anterior teeth are related to non-dietary tooth-use behaviors, or using the teeth as a tool or third hand which causes more limited striations at the labial surface.
\end{abstract}

Keywords: Food production, Evolution, Human dentition, Tooth microwear

\section{Background}

Modern-day humans, Homo sapiens, have evolved orofacial features from the early hominins, which made the human jaw smaller followed by the overall tooth size reduction (Das et al. 2019). The second molars were the largest among the molars in the early hominins; meanwhile, in modern human dentition, the first molars are the largest among the molars, with the reduction of the overall tooth. The analysis of the tooth shapes and sizes, enamel shapes, and the dental microwear along with dental biomechanics, suggested there were changes in the dietary capacities of the early hominins that helped them

\footnotetext{
*Correspondence: arofi.kurniawan@fkg.unair.ac.id

${ }^{1}$ Department of Forensic Odontology Faculty of Dental Medicine Universitas Airlangga, J. Mayjen. Prof. Dr. Moestopo 47, Surabaya 60132, Indonesia

Full list of author information is available at the end of the article
}

survive in climatic variability (Emes et al. 2011; JiménezArenas et al. 2014; Marini et al. 2020).

The decrease of jaw size was mostly on the account of the dietary habit changes of the species. The changes in the dietary habits led to smaller, less prominent jaws followed by smaller teeth and non-projected canines altogether with a smaller face in the Homo sapiens (Das et al. 2019). As humans learned to soften foods with the tools for cutting and grinding, the need for carnivore adaptive characteristics in which strong jawbones, large canines, and stronger masticatory included, tend to decrease. Also, there have been well-defined changes in the position of the temporomandibular joint to the changes in dietary habits and food processing (Emes et al. 2011; Humphrey 2017). The current review aims to discuss the effects of dietary changes on the evolution of human dentition.

For this purpose, this review included studies on the evolution of human dentition, dental microwear analysis, 
and the causes of the evolution of human dentition in terms of dietary habits and tool usage. The online literature search in the PubMed database was conducted with a combination of search terms were constructed from "diet," "tooth evolution," "dental microwear," and "microwear analysis." In addition to online literature searches, reference lists from all the included articles were manually examined for further full-text studies. This review included research and review articles published during the last 10 years period (2011-2021). All articles focused on human tooth evolution studies and were written in English. This review included the full-text available articles based on search filters in the PubMed database.

\section{Main text}

\section{Brief introduction of evolution}

Evolution is defined as the gradual development of inheritable traits of humankind over successive generations. Evolutionary processes generate diversity at all levels of biological organization. Charles Darwin in the mid-nineteenth century proposed that evolution occurs because of a natural selection phenomenon. The Darwin theory of natural selection explained that organisms produce more offspring that can survive in their environment, with better physically equipped to survive, grow, and reproduce. All life on earth shares a common ancestor known as the last universal ancestor. Through the discipline of population genetics, the modern evolutionary synthesis integrated classical genetics with Darwin's theory of evolution by natural selection in the early twentieth century. Evolution is a cornerstone of modern science, widely accepted as one of the most consistently established of all scientific facts and theories, supported by evidence from not only from the biological sciences but also from anthropology, psychology, astrophysics, chemistry, geology, physics, mathematics, and other scientific disciplines, as well as behavioral and social sciences (Ashraf and Sarfraz 2016; National Geographic Society 2019).

\section{Human dentition}

The primary function of dentition in mammals is to grasp and crush food, which is supported by the extreme hardness of tooth tissues and an appropriate crown shape in different tooth classes. Teeth also play a role in speech articulation and facial appearance in humans. Human dentition is classified as heterodont and diphyodont. The heterodonty is reflected by four tooth classes: incisors, canines, premolars, and molars. During human life, diphyodont is represented by two generations of functional teeth: there are 20 deciduous (milk or lacteal) teeth and 32 permanent (adult) teeth (Hovorakova et al. 2018; Wang et al. 2019).
From the anthropological perspective, dentition is one of the most important aspects of human evolution. Dentition is a focal point in many comparative and evolutionary population studies due to its stability and durability towards the environmental factor. Certain morphological features of the tooth are known to exhibit population variation and can be used to distinguish the ancestry. Dental traits such as the shoveling incisor, Carabelli cusp, hypocone, and peg-shaped teeth can be used to determine the ethnicity of the individual. Teeth have also been observed to provide important evidence regarding the habits and occupations of individuals (Kjær 2014; Krishan et al. 2015; Christensen et al. 2019; Kurniawan et al. 2020a).

Human dentition also plays an important role in individual identification. The scientific basis of dental identification is the uniqueness of human dentition and the fact that no two oral cavities are alike even in monozygotic twins. Tooth variation such as morphological characteristics, color, shape, tooth wear pattern, and dental anomalies can give further clues regarding the individual identity. As the hardest tissue in the human body, teeth can survive in extreme conditions that involve chemical, physical, and thermal trauma. Forensic odontologists work with other experts, such as dental anthropologists to analyze numerous important information from teeth associated with sex determination, age estimation, ethnic origin, bitemark analysis, and dental records comparison (Krishan et al. 2015; Kurniawan et al. 2020b).

\section{Evolutionary processes of the human dentition}

Most vertebrate species have teeth or tooth-like structures called denticles, with non-mammalian vertebrate teeth differing from their mammalian counterparts by having no roots and connecting directly to the jaw bone by ankylosis or fibrous tissue. Mammalian teeth, on the other hand, possess roots and connect to the jaws by periodontal ligaments. Humans are vertebrates thought to share the same mammalian ancestor as mice, whose each dental arch possesses 6 incisors, 2 canines, 8 premolars, and 6 molars (Jheon et al. 2013; Enault et al. 2018).

Differences between humans and other hominid species are also apparent were some professionals attributed causes like dietary changes to these major anatomical changes (Ungar 2012). One of the most noticeable differences between Homo sapiens (modern humans) and early hominins is the protruding chin, which is thought to be the result of a decrease in heavy dental use and the use of tongue and oral musculature to form early languages, which resulted in the protruding chin (Emes et al. 2011; Daegling 2012).

The jaw reduction phenomenon from the early hominins to modern humans is usually linked to the advancements towards agricultural cultures as a replacement for 
hunting and gathering culture. Smaller oral space and sharp teeth are also believed to be a result of the creation of a language that needed a flexible oral system and is also maintained by the creation of softer, more processed foods (Emes et al. 2011; Polanski 2011).

Another change that is also apparent in modern humans, tooth-wise, is the decrease of tooth size in comparison to their close relatives. Megadontia in australopiths is attributed to the need of processing mechanically challenging foods and the need for the larger cheek area, while in Homo, the reduction of molar size is attributed to the use of tools and less challenging foods, as well as to avoid an avalanche in foods (Ungar 2012).

Differences in tooth sizes concerning the other teeth are also apparent. In early hominins, second molars are the largest compared to the other molars while in Homo the first molar is the largest. The canines also differ with sex in early hominins, where males have smaller canines (Emes et al. 2011; Guatelli-Steinberg 2018).

In dental structure, early hominins have thicker enamel layers to cover their teeth than modern humans. This is believed to provide stronger reinforcement for their harder-textured diet (Ungar 2012). The tooth calcification of early hominins also has more resemblances to apes than to humans, which is also contributed by the progression of lifestyle changes (Smith 2013).

Lastly, there are also differences in occlusal morphology. Modern humans have helicoidal occlusal planes, where the anterior teeth slope upwards palatally and the posterior teeth slope upwards buccally (Emes et al. 2011). This difference is also caused by the differences in cusps shapes. The molars of Australopithecus have a blunt cusp shape to chew brittle and hard foods like flowers, nuts, and some fruits, whereas the Homo has sloping surfaces and less bulbous cusps for slicing items better (Ungar 2012).

\section{Dental microwear analysis}

Dietary reconstruction is an important aspect of paleoanthropology research because food can be used as a biomarker in human evolution and cultural development (Petraru et al. 2020). The microscopic wear pattern left on the occlusal surfaces of teeth during the masticatory process is the primary focus of dental microwear analysis. Its evaluation is based on the morphology, abundance, direction, and distribution of the microscopic marks on the enamel surfaces (Scott and Halcrow 2017; Strani et al. 2018).

Various methods of dental microwear analysis have been developed relies on two-dimensional (2D) and three-dimensional (3D) imaging techniques. The scanning electron microscope and the examination of visible individual features are the most common 2D imaging technique. Dental microwear analysis can be performed using a 2D imaging technique by molding and casting process of teeth according to a standardized method. The tooth's surface is cleaned before being molded with a polyvinyl siloxane compound and cast with clear epoxy resin. The casts were photographed using an Insight Spot 4-megapixels camera and a Zeiss Stemi light stereomicroscope (Mihlbachler et al. 2012). Dental microwear analysis has been recognized as an accurate tool for studying diets in early hominins. Nonetheless, the sample sizes for some groups are small, thereby lowering our belief that the results are representative of a particular taxon. The limited samples size also makes it difficult to assess variation within species (Ungar 2012; DeSantis 2016).

The surface's wear on the teeth is usually analyzed using a 3D optical profiler and either scale-sensitive fractal analysis (SSFA) or International Standards Organization (ISO) variables to assess surface properties. Dental microwear analysis scans 3D microwear textures with white or blue light. The resulting point clouds were then examined using ISO parameters or using SSFA software to identify tooth surfaces (DeSantis 2016).

The dietary hypothesis based on the occlusal tooth microwear study could be tested by analyzing the microwear pattern of the buccal teeth. The occlusal microwear pattern varies between shear and grinding facets on the same tooth and intra-facet variability in molars has been shown to depend on various masticatory processes (Martínez et al. 2016; Alrousan et al. 2019). There are grinding facets on the occlusal surface in molars that happened because of the power stroke when chewing (Fig. 1) (Scott and Halcrow 2017).

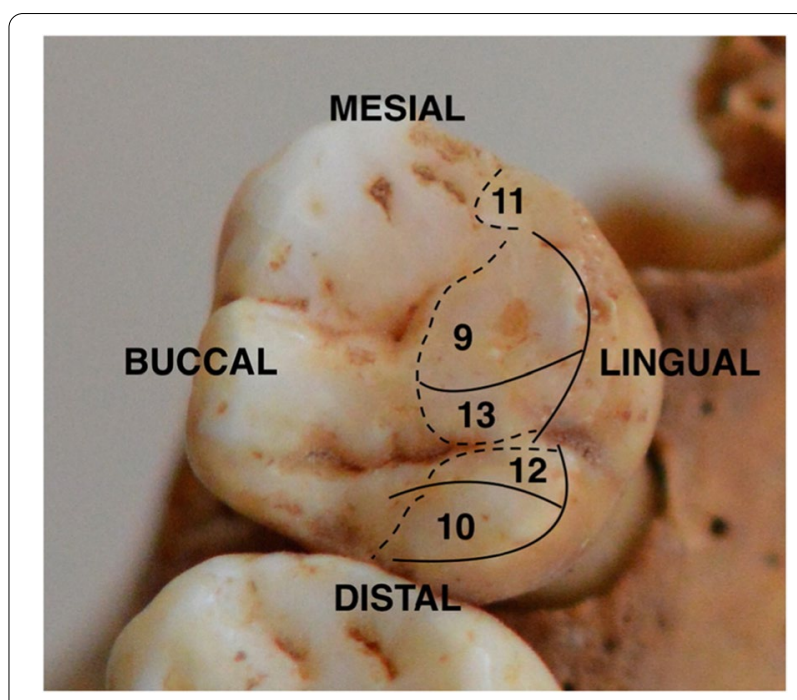

Fig. 1 Microwear on grinding facet (Scott and Halcrow 2017) 
The buccal microwear pattern on the enamel surface of primate teeth shows much higher interspecific variability than intraspecific variability. The density and length of the striation by orientation category on the buccal surface of the enamel varies depending on the ingested food and the abrasive potential of chewed food particles, including plant foods and silica dust that enter the food during procurement and processing (Martínez et al. 2016; Petraru et al. 2020).

\section{Diets and human dentition evolution}

Diet influences the evolution of human dentition. To make conclusions about ancient diets, several approaches were taken, one of which is the shape of the molar cusp that might suggest adaptations to a leaf-or fruit-based diet, or in general (Antón et al. 2014; Ortiz et al. 2018). The transition from a hunter-gatherer society to agriculture was accompanied by a notable decrease in the frequency of tooth wear. Populations that undergo agricultural intensification began to consume more refined food sources, thereby reducing wear rates. Agricultural communities tend to have more angled wear while the hunter-gatherer community presented evenly distributed flat wear (Michael et al. 2017; Marini et al. 2020).

Dental microwear or scratches and pits on the enamel surface indicate direct evidence for dietary behavior. Those pits formed due to the fracture of food processing or tooth-used behaviors. For example, the large and deep pits molar surface showed a solid food consumption, such as seeds or nuts, while scratches indicate shearing tough objects, like plants or insects. The microwear can also show variations in the diet, which are influenced by environmental conditions. Neanderthal in cold, open steppe climate showed dependence on meat resources. Meanwhile, those with forest conditions showed dependence on the plant resource base, which had the increasing sign of abrasive loads (Krueger 2015; Schmidt 2015).

Another study shows that vertical and horizontal scratches were useful in differentiating human diets. Most groups of carnivorous humans showed a higher proportion and number of vertical scratches, along with a lower percentage of horizontal scratches. The opposite happened for predominantly vegetarian individuals, whereas populations with mixed diets (e.g., Bushmen, Australia) have mean scores for both indications (Scott 2018; Corona et al. 2018). Analyzes of dental microwear can be divided into posterior teeth microwear and anterior teeth microwear. Those categories can indicate the tendency of their functions. Posterior teeth are more closely related to diet, while anterior teeth are related to non-dietary tooth-use behaviors, or using the teeth as a tool or third hand (Schmidt et al. 2020).
To analyze incisor microwear, anisotropy measurements are used. Anisotropy measures the amount of forwarding direction after a scattering event (Fernandez-Oliveras et al. 2012). When the anterior teeth are used to incise large food items, the abrasive adherent to the food will drag up the labial surface and create apico-cervically oriented striations. This would result in high anisotropy values. The low anisotropy value is used to indicate the non-dietary anterior teeth use. Its use, such as tool retouching, clamping, and grasping, causes more limited striations at the labial surface (Burnett 2015).

\section{Conclusions}

Diet has a significant impact on the evolution of human dentition. Various methods, such as scanning electron microscopy and scale-sensitive fractal analysis, can be used to investigate the dietary hypothesis based on dental microwear analysis. The occlusal tooth microwear study could be tested by analyzing the microwear pattern (shear, striation, pattern) of the buccal teeth. Large and deep pits on the molar surface indicated the consumption of solid food, such as seeds or nuts, while scratches indicated the shearing of tough objects, like plants or insects. Carnivorous humans had a higher proportion and number of vertical scratches, with a lower percentage of horizontal scratches. Vegetarian individuals showed a higher percentage of horizontal scratches, with a lower proportion of vertical scratches. The average score of vertical and horizontal scratches is more common in populations with mixed diets. Posterior teeth are more closely associated with diet, whereas anterior teeth are associated with non-dietary tooth-use behaviors, such as using the teeth as a tool or third hand, which results in more limited striations at the labial surface.

\section{Abbreviations}

2D: Two-dimension; 3D: Three-dimension; ISO: International Standards Organization; PDE: Percentage dentine exposure; SSFA: Scale-sensitive fractal analysis.

\section{Acknowledgements \\ Not applicable}

\section{Authors' contributions}

AK, SMM, NN, MAH, DAS, and PT contributed to the data and reference collection. AK is the supervisor of the present study. AK, SMM, NN, MAH, DAS, and PT contributed to drafting the manuscript. The authors have read and approved the final manuscript.

\section{Funding}

Not applicable.

Availability of data and materials

Not applicable. 


\section{Declarations}

Ethics approval and consent to participate

Not applicable

\section{Consent for publication}

Not applicable.

\section{Competing interests}

The authors declare that they have no competing interests.

\section{Author details}

${ }^{1}$ Department of Forensic Odontology Faculty of Dental Medicine Universitas Airlangga, J. Mayjen. Prof. Dr. Moestopo 47, Surabaya 60132, Indonesia. ${ }^{2}$ Faculty of Dental Medicine Universitas Airlangga, Surabaya, Indonesia.

Received: 5 May 2021 Accepted: 25 January 2022

Published online: 01 February 2022

\section{References}

Alrousan M, Estebaranz-Sánchez F, Al-Shorman A et al (2019) Buccal dental microwear as an indicator of dietary habits and dietary adaptation of the byzantine people of Jordan. Anthropol Anz 76:352-362. https://doi.org/10. 1127/anthranz/2019/0971

Antón SC, Potts R, Aiello LC (2014) Evolution of early Homo : an integrated biological perspective. Science (80-) 345:1236828. https://doi.org/10.1126/ science. 1236828

Ashraf MA, Sarfraz M (2016) Biology and evolution of life science. Saudi J Biol Sci 23:S1-S5. https://doi.org/10.1016/j.sjbs.2015.11.012

Burnett SE (2015) Crown Wear. In: Irish JD, Scott GR (eds) A companion to dental anthropology. Wiley Blackwell, West Sussex, pp 413-432

Christensen AM, Passalacqua NV, Bartelink EJ (2019) Human osteology and odontology. In: Forensic anthropology. Elsevier, pp 33-76

Corona A, Ubilla M, Perea D (2018) New records and diet reconstruction using dental microwear analysis for Neolicaphrium recens Frenguelli, 1921 (Litopterna, Proterotheriidae). Andean Geol 46:153. https://doi.org/10.5027/ andgeoV46n1-3136

Daegling DJ (2012) The human mandible and the origins of speech. J Anthropol 2012:201502. https://doi.org/10.1155/2012/201502

Das H, Motghare V, Singh M (2019) Human evolution of the teeth \& jaws: a mouthful of history. Int J Oral Heal Med Res 5:32-36

DeSantis LRG (2016) Dental microwear textures: reconstructing diets of fossil mammals. SurfTopogr Metrol Prop 4:023002. https://doi.org/10.1088/2051$672 X / 4 / 2 / 023002$

Emes Y, Aybar B, Yalcin S (2011) On the evolution of human jaws and teeth: a review. Bull Int Assoc Paleodont 5:37-47

Enault S, Muñoz D, Simion P et al (2018) Evolution of dental tissue mineralization: an analysis of the jawed vertebrate SPARC and SPARC-L families. BMC Evol Biol 18:127. https://doi.org/10.1186/s12862-018-1241-y

Fernandez-Oliveras A, Rubiño M, Perez MM (2012) Scattering anisotropy measurements in dental tissues and biomaterials. J Eur Opt Soc Rapid Publ 7:12016. https://doi.org/10.2971/jeos.2012.12016

Guatelli-Steinberg D (2018) Dental anthropology in the AJPA : its roots and heights. Am J Phys Anthropol 165:879-892. https://doi.org/10.1002/ajpa. 23352

Hovorakova M, Lesot H, Peterka M, Peterkova R (2018) Early development of the human dentition revisited. J Anat 233:135-145. https://doi.org/10.1111/joa. 12825

Humphrey L (2017) Palaeontology: evolution with teeth. Nature 545:26-27. https://doi.org/10.1038/545026a

Jheon AH, Seidel K, Biehs B, Klein OD (2013) From molecules to mastication: the development and evolution of teeth. Wiley Interdiscip Rev Dev Biol 2:165-182. https://doi.org/10.1002/wdev.63

Jiménez-Arenas JM, Pérez-Claros JA, Aledo JC, Palmqvist P (2014) On the relationships of postcanine tooth size with dietary quality and brain volume in primates: implications for hominin evolution. Biomed Res Int 2014:1-11. https://doi.org/10.1155/2014/406507

Kjær I (2014) Mechanism of human tooth eruption: review article including a new theory for future studies on the eruption process. Scientifica (Cairo) 2014:1-13. https://doi.org/10.1155/2014/341905
Krishan K, Kanchan T, Garg AK (2015) Dental evidence in forensic identification - an overview, methodology and present status. Open Dent J 9:250-256. https://doi.org/10.2174/1874210601509010250

Krueger KL (2015) Dentition, behavior, and diet determination. In: Irish JD, Scott GR (eds) A companion to dental anthropology. Wiley Blackwell, West Sussex, pp 396-411

Kurniawan A, Agitha SRA, Margaretha MS et al (2020a) The applicability of Willems dental age estimation method for Indonesian children population in Surabaya. Egypt J Forensic Sci 10:5. https://doi.org/10.1186/s41935-020-0179-6

Kurniawan A, Yodokawa K, Kosaka M et al (2020b) Determining the effective number and surfaces of teeth for forensic dental identification through the 3D point cloud data analysis. Egypt J Forensic Sci 10:3. https://doi.org/10. 1186/s41935-020-0181-z

Marini MI, Angrosidy H, Kurniawan A, Margaretha MS (2020) The anthropological analysis of the nasal morphology of Dayak Kenyah population in Indonesia as a basic data for forensic identification. Transl Res Anat 19:100064. https:// doi.org/10.1016/j.tria.2020.100064

Martínez LM, Estebaranz-Sánchez F, Galbany J, Pérez-Pérez A (2016) Testing dietary hypotheses of east african hominines using buccal dental microwear data. PLoS One 11:e0165447. https://doi.org/10.1371/journal.pone.0165447

Michael DE, Eliopoulos C, Manolis SK (2017) Exploring sex differences in diets and activity patterns through dental and skeletal studies in populations from ancient Corinth, Greece. HOMO 68:378-392. https://doi.org/10.1016/j.jchb. 2017.09.002

Mihlbachler M, Beatty B, Caldera-Siu A et al (2012) Error rates and observer bias in dental microwear analysis using light microscopy. Palaeontol Electron 15:1-22. https://doi.org/10.26879/298

National Geographic Society (2019) Theory of evolution https://www.nationalge ographic.org/encyclopedia/theory-evolution/. Accessed 24 Oct 2021

Ortiz A, Bailey SE, Schwartz GT et al (2018) Evo-devo models of tooth development and the origin of hominoid molar diversity. Sci Adv 4:eaar2334. https://doi.org/10.1126/sciadv.aar2334

Petraru O-M, Groza V-M, Lobiuc A et al (2020) Dental microwear as a diet indicator in the seventeenth-century human population from lasi City, Romania. Archaeol Anthropol Sci 12:184. https://doi.org/10.1007/s12520-020-01159-2

Polanski JM (2011) Morphological integration of the modern human mandible during ontogeny. Int J Evol Biol 2011:545879. https://doi.org/10.4061/2011/ 545879

Schmidt CW (2015) Estimating age, sex, and individual ID from teeth. In: Irish JD, Scott GR (eds) A companion to dental anthropology. Wiley Blackwell, West Sussex, pp 362-376

Schmidt CW, El Zaatari S, Van Sessen R (2020) Dental microwear texture analysis in bioarchaeology. In: Schmidt CW, Watson J, TBT-DW in E and BC (eds) Dental Wear in evolutionary and biocultural contexts. Elsevier, pp 143-168

Scott GR (2018) Dental anthropology. In: Smith C (ed) Encyclopedia of global archaeology. Springer International Publishing, Cham, pp 1-8

Scott RM, Halcrow SE (2017) Investigating weaning using dental microwear analysis: a review. J Archaeol Sci Rep 11:1-11. https://doi.org/10.1016/j. jasrep.2016.11.026

Smith TM (2013) Teeth and human life-history evolution. Annu Rev Anthropol 42:191-208. https://doi.org/10.1146/annurev-anthro-092412-155550

Strani F, Profico A, Manzi G et al (2018) MicroWeaR: a new R package for dental microwear analysis. Ecol Evol 8:7022-7030. https://doi.org/10.1002/ece3. 4222

Ungar PS (2012) Dental evidence for the reconstruction of diet in african early homo. Curr Anthropol 53:S318-S329. https://doi.org/10.1086/666700

Wang F, Li G, Wu Z et al (2019) Tracking diphyodont development in miniature pig in vitro and in vivo. Biol Open 8:bio037036. https://doi.org/10.1242/bio. 037036

\section{Publisher's Note}

Springer Nature remains neutral with regard to jurisdictional claims in published maps and institutional affiliations. 